\title{
Editorial
}

\section{Science journalism to face a demand for renewal}

\begin{abstract}
A workshop on science journalism organised at SISSA of Trieste, Italy a few weeks ago outlined scenarios that should serve as a source for debate among professionals and scholars to grasp how information activities regarding science, medicine and technology will evolve in the next few years. It is a time of great uncertainty, yet a common path to venture through can be made out: the new science journalism should meditate on a different concept of science, an indepth conceptualisation of different audiences, alternative narrations and its role in the democratisation of knowledge within a knowledge-based society.
\end{abstract}

About a month ago, within the activities of SISSA's Ics research group (http://ics.sissa.it) - which comprises many members of Jcom's editorial staff - we organised a workshop called Science Journalism and Power in $21^{\text {st }}$ Century.

In the past few years, Ics has contributed to the practical-theoretical debate concerning innovative ways to make medical, scientific and technologic knowledge circulate. The future of science journalism is one of the themes that has recently been in our focus. We have been trying to approach the subject not only in light of the employment issue that has been affecting the industry. Without minimising the concerns related to the cut in jobs for science journalists, we believe it is important to address the phenomenon from another viewpoint too, starting from an apparent contradiction: how can a society and an economy based on knowledge possibly do without professional figures able to socially enhance the "intellectual capital" made up of scientific and technologic knowledge? In other words, can we really do without people who have the skills to express and to transform knowledge into information, especially in a historical age in which ideas, talent, creativity should matter the most for economic well-being?

Based on these questions, we have decided to organise an event in which to discuss how the big blows in the communication system and in the science-society relationship are now changing the logic of power in the distribution, appropriation and circulation of the information once basically considered as a prerogative of science journalism.

The website devoted to the meeting contains the videos for the speeches (http://www.mappetrieste.it/cms/video) and a blog (http://www.mappetrieste.it $/ \mathrm{cms} / \mathrm{blog}$ ) published about a month prior to the meeting. And in this Jcom issue we are publishing some interviews with the protagonists of the workshop. We are also planning a call for abstracts based on the reports and the debates carried out over the day.

In the next few months, we plan to keep following the developments of the practical-theoretical discussion on science journalism as we believe we are now facing a turning point. Now it is clear that the myth of the journalist stealing the fire of knowledge to save the general public from ignorance simply telling science facts is going through a difficult time. On the other hand, it is also clear that, for the moment, no professional figures stand out to add on to or replace the translator's work.

Whereas there are not any other myths available, it appears that meetings such as the workshop organised last month do confirm what emerges from the most detailed analyses and in other international forums: a change is demanded, and there is at least one shared strategy to face ongoing changes which is called enlargement.

First and foremost, enlargement of the idea of science.

Historian Steven Shapin affirms that addressing the issue of identifying science's role in the contemporary world corresponds to the issue of describing the way we live today: what to believe in, whom to trust, what to do. ${ }^{1}$ This is a perspective that goes well with the scenarios of a change in science journalism. It does point to a destination where we will increasingly need information professionals able to guide us through different types of expertise, to identify relevant experts with an independent authority, aside from reporters telling about discoveries and the scientific method.

Additionally, there is an increasingly urgent need to enlarge the concept of science audiences. Whereas it is demonstrated that it is too simplistic to conceptualise these audiences as pre-existing to science 
communication activities, there has not been enough debate on the needs science communication should meet for them.

Science journalism has traditionally focussed much on product accuracy believing its intrinsic quality was basically everything it needed. However, it has not debated enough on what meaning and role readers would attach to it. It is a model that has worked well as long as its fundamental role was to draw a demarcation line between science and non-science or to promote the public understanding of science. Today, this function falters as an increasingly higher number of citizens of the knowledge-based society want to have their say on what science does and wants to do, and as it is threatened by the even more powerful digital social media. The authors of one of the few studies available on how journalism can save public participation in science issues, recently published in Journalism Practice, ${ }^{2}$ maintain that journalism has missed the big chance of presenting itself and gain ground as the privileged discussion forum to meet the pressing demand for science's democratisation that has emerged in the past few years. This space should be taken by a new science journalism.

Finally, it is not difficult to foresee that future information professionals working in the field of science, medicine, technology should play a higher number of roles than in the past. Similarly to what may happen to journalism in general, they will have to look for news and be able to aggregate them, but also to organise events, do some marketing, work as cultural mediators to facilitate the dialogue between science and society.

This fusion is still far away, but it is not a far-fetched hypothesis to think this type of professional figure will be extremely valuable in the market of the knowledge-based society and economy.

Translated by Massimo Caregnato

Nico Pitrelli

\section{Notes and references}

1 S. Shapin (2007), Science and the Modern World, in E. J. Hackett, O. Amsterdamska, M. Lynch and J. Wajcman (eds.), The Handbook of Science and Technology Studies, The MIT Press, U.S.A., pg. 444.

2 A. Nguyen and S. McIlwaine (2011), Who wants a voice in science Issues - and why?. A survey of European citizens and its implications for science journalism, Journalism Practice 6(1): 1-17.

How TO CITE: $\quad$ N. Pitrelli, Science journalism to face a demand for renewal, Jcom 09(04) (2010) E. 